\title{
Dynamics of active potential bacterial and fungal interactions in the assimilation of acidobacterial EPS in soil
}

\author{
Ohana Y.A. Costa ${ }^{\text {a,b }}$, Agata Pijl ${ }^{\text {a }}$, Eiko E. Kuramae ${ }^{\text {a,c,* }}$ \\ ${ }^{\text {a }}$ Netherlands Institute of Ecology (NIOO-KNAW), Department of Microbial Ecology, P.O. Box 50, 6700, AB, Wageningen, the Netherlands \\ ${ }^{\mathrm{b}}$ Institute of Biology (IBL), Leiden University, Leiden, the Netherlands \\ ${ }^{\mathrm{c}}$ Ecology and Biodiversity, Institute of Environmental Biology, Utrecht University, Padualaan 8, 3584, CH, Utrecht, the Netherlands
}

\section{A R T I C L E I N F O}

\section{Keywords:}

Acidobacteria

EPS

Stable isotope probing

Planctomycetes

Co-occurrence

Carbohydrates

\begin{abstract}
A B S T R A C T
Acidobacteria are one of the most abundant and ubiquitous bacterial phyla in soil, but the mechanisms underpinning their ecological success remain unknown. Acidobacteria produce copious amounts of extracellular polymeric substances (EPS) with unique sugar composition that can be used as a nutrient source for other microorganisms. Here, we investigated the assembly and potential interactions of the active bacterial and fungal communities in soil treated with the EPS of the Acidobacteria Granulicella sp. strain WH15 (WH15EPS) as a carbon source by the stable isotope probing (SIP) approach during a 35-day period. WH15EPS was mainly assimilated by Planctomycetes, Verrucomicrobia, Ascomycota and Basidiomycota and analysis suggested overall relationships between the kingdoms. Our study revealed active potential interactions between microorganisms in their natural habitat. In addition, the structure of the co-occurrence network of active microorganisms able to metabolize WH15EPS differed from those of the control treatments, demonstrating that hidden potential interactions can be unraveled by more specific and targeted metabolism studies.
\end{abstract}

\section{Introduction}

Acidobacteria are one of the most abundant bacterial phyla in soil, constituting $20-50 \%$ of the soil bacterial community (Kuramae et al., 2012; Navarrete et al., 2013; Pan et al., 2014; Kielak et al., 2016a, 2016b). However, little information is available on the physiology, ecological function, and impact of Acidobacteria on the soil environment (Kielak et al., 2016a) because their slow growth under standard laboratory conditions has resulted in a relatively small number of cultured representatives. Consequently, the factor(s) responsible for the prevalence and successful adaptation of Acidobacteria and their relationships with other soil-inhabiting microbes remain unknown (Kielak et al., 2016a).

Network analysis studies using culture-independent sequence data have shown that Acidobacteria species co-occur with other Acidobacteria, Proteobacteria, Actinobacteria and Planctomycetes (Lupatini et al., 2014; Navarrete et al., 2015). However, no study has investigated the active potential interactions of Acidobacteria with other bacteria and/or fungi in co-occurrence networks associated to the use of an acidobacterial biopolymer.

Acidobacteria such as strains Ellin6076 and Ellin345 (Ward et al.,
2009), Terriglobus tenax (Whang et al., 2014) and Granulicella sp. strains WH15 and 5B5 (Kielak et al., 2017) produce extracellular polymeric substances (EPS). EPS are biopolymers secreted by a variety of microorganisms and mainly comprise carbohydrates, proteins and DNA. EPS play an important role in numerous bacterial physiological traits and ecological adaptations, especially in bacteria living in communities and with complex interactions with other organisms. The role of EPS depends on the ecological niche and natural dwelling environment of the microorganism (Costa et al., 2018). EPS may positively impact bacterial survival and function by enhancing bacterial quorum sensing, thus stimulating important metabolic activities and consequently promoting syntrophic interactions (Wingender et al., 1999). EPS production has been implicated in the long-term survival of Acidobacteria in several environments due to its protective properties (Kielak et al., 2017). Among Acidobacteria, EPS have only been isolated and chemically characterized from Granulicella sp. strains WH15 and 5B5, and the emulsion capacity of these EPS suggests potential industrial and environmental bioremediation applications (Kielak et al., 2017). EPS also serve as nutrient sources for other microorganisms (Flemming and Wingender, 2010), and the use of EPS from microbes other than Acidobacteria as a nutrient has been investigated in cross-feeding

\footnotetext{
* Corresponding author. Netherlands Institute of Ecology (NIOO-KNAW), Droevendaalsesteeg 10, 6708, PB, Wageningen, the Netherlands.

E-mail address: e.kuramae@nioo.knaw.nl (E.E. Kuramae).
} 
experiments.

The assimilation of EPS as a carbon source by active microorganisms can be investigated with stable isotope probing (SIP). SIP is a powerful technique that evaluates the incorporation of compounds labeled with heavy isotopes, such as ${ }^{13} \mathrm{C},{ }^{18} \mathrm{O}$ and ${ }^{15} \mathrm{~N}$, into the cell components of microorganisms metabolizing a specific substrate. Thus, SIP reflects the active microorganisms involved in the metabolism of a specific compound. SIP has been used to investigate the microorganisms responsible for the degradation of different compounds in many environments (Madsen, 2006), including labeled glucose (Verastegui et al., 2014), methanol (Ginige et al., 2004), phenol (Padmanabhan et al., 2003), salicylate and anthracene (Singleton et al., 2005). The use of SIP to investigate EPS has been limited to a single study identifying microorganisms that assimilate the EPS of Beijerinckia indica (Wang et al., 2015). In this context, in the present study, EPS from Granulicella sp. strain WH15 was applied as a carbon source to soil sampled from the site where this strain was isolated, and the active bacterial and fungal community assemblages and potential interactions in the soil during a 35-day period were evaluated by SIP. We hypothesized that only a selection of specific microbes with a wide range of glycoside hydrolases would be able to incorporate WH15EPS.

\section{Material and methods}

\subsection{Soil sampling}

Four organic topsoil samples were collected in the spring of 2017 from the Wolfheze forest in the Netherlands. Samples were taken from topsoil $(0-5 \mathrm{~cm})$ adjacent to fallen tree trunks. Wolfheze forest is a mixed forest site (managed by Natuurmonumenten) close to Doorwerth village, the Netherlands ( $51^{\circ} 58^{\prime} 60^{\prime \prime}, \mathrm{E} 15^{\circ} 47^{\prime} 60^{\prime \prime}$, altitude $49 \mathrm{~m}$ ). The forest has developed on glacial sandy deposits with oak (Quercus robur L.), beech (Fagus sylvatica L.), birch (Betula sp.) and pine (Pinus sylvestris L.) as major species (Valášková et al., 2009). In order to collect samples, we removed the superficial litter layer and collected the hummus and fermentation layers of the soil, rich in organic matter, with a shovel. The sampling was performed in regions close to tree trunks, since Granulicella strains can be also isolated from fallen oak trunks. (Valášková et al., 2009).

The collected samples were pooled, sieved (4 mm mesh) and immediately used for SIP incubation with EPS from Granulicella sp. strain WH15 (WH15EPS). The physicochemical properties of the organic topsoil samples were determined by Eurofins Agro BV, Wageningen, NL. The organic topsoil employed in the experiment presented $\mathrm{pH} 3.1 \pm 0.1$, $55 \pm 3.5 \%$ of organic matter, $16.5 \pm 3.2 \mathrm{~g} \mathrm{~kg}^{-1}$ of total N, $352 \pm 4.2 \mathrm{mg} \mathrm{kg}$ ${ }^{-1}$ of available $\mathrm{N}$, cation exchange capacity (CEC) of $21.4 \pm 4.2 \mathrm{cmol} \mathrm{kg}^{-1}$, $42.7 \pm 6.4 \mathrm{mg} \mathrm{kg}^{-1}$ of available $\mathrm{P}, \mathrm{C} / \mathrm{N}$ ratio of $20 \pm 5.7$. Maximum water holding capacity (WHC) of sieved organic topsoil was $1.85 \pm 0.03 \mathrm{~g} \mathrm{~g}^{-1}$ dry soil. Organic matter, Total $\mathrm{N}$ and CEC were measured by Nearinfrared (NIR) reflectance spectroscopy (triple-short calibration); available $\mathrm{P}$ was extracted with acid ammonium oxalate solution $(\mathrm{pH} \mathrm{3)}$ and measured by Inductively Coupled Plasma Atomic Emission Spectrometry (ICP-AES); $\mathrm{pH}$ was measured by potentiometry-CaCl 2 . Maximum WHC was measured by soaking $25 \mathrm{~g}$ of the organic topsoil soil $(\mathrm{n}=8)$ in $25 \mathrm{ml}$ deionized water and then draining for $5 \mathrm{~h}$. Next, organic topsoil samples were dried at $105{ }^{\circ} \mathrm{C}$ for $24 \mathrm{~h}$. WHC was determined by the difference between the mass of the oven-dried and the wet topsoil samples.

\section{2. $\left[{ }^{13} \mathrm{C}\right]$-labeled and unlabeled EPS production}

Granulicella sp. strain WH15 was grown on PSY5 solid medium (Campanharo et al., 2016) containing $3 \%$ (wt/vol) fully ${ }^{13} \mathrm{C}$-labeled glucose as the sole carbon source or unlabeled glucose for unlabeled control EPS production. The plates were incubated at $30{ }^{\circ} \mathrm{C}$ for 3 days and then at $20^{\circ} \mathrm{C}$ for 27 days. The polysaccharide portion of EPS was extracted and purified according to the formaldehyde-NaOH method described by Liu and Fang (2002), with modifications. The method was chosen due to the fixing properties of formaldehyde, which prevents cell lysis. EPS and cells of strain WH15 $(\sim 5 \mathrm{ml})$ were scraped from the plates into $50-\mathrm{ml}$ Falcon tubes, and the volume was adjusted to $10 \mathrm{ml}$ with sterile water. Sixty microliters of $36.5 \%$ formaldehyde was added to each sample and incubated at $4{ }^{\circ} \mathrm{C}$ for $1 \mathrm{~h}$. Next, $4 \mathrm{ml}$ of $1 \mathrm{M} \mathrm{NaOH}$ was added and incubated at $4{ }^{\circ} \mathrm{C}$ for $3 \mathrm{~h}$. The cells were then pelleted by centrifugation at $9000 \times g$ for $40 \mathrm{~min}$. The supernatants were filtered (0.2 $\mu \mathrm{m}$ membranes, Millipore) at room temperature, and monosaccharides and other low molecular weight metabolites were removed by dialysis in SnakeSkin ${ }^{\mathrm{TM}}$ Dialysis Tubing (3500 Da) (Thermo Fisher Scientific, Massachusetts, USA) against demineralized water at $4{ }^{\circ} \mathrm{C}$ for $48 \mathrm{~h}$. The solutions were frozen at $-80^{\circ} \mathrm{C}$ for $12 \mathrm{~h}$ and then freeze-dried at $-80{ }^{\circ} \mathrm{C}$ for $72 \mathrm{~h}$. Before freeze-drying, the DNA concentration in the EPS solution was determined in a Qubit fluorometer using a broad-range Quant-iT ${ }^{\mathrm{TM}}$ dsDNA Assay Kit (Invitrogen, Carlsbad, California, USA). EPS protein concentrations were determined by a Pierce ${ }^{\mathrm{TM}}$ Modified Lowry Protein Assay Kit (Thermo Fisher Scientific, Massachusetts, USA). The total carbohydrate content was estimated by the phenol-sulfuric acid method (DuBois et al., 1956) modified for 96-well plates (Masuko et al., 2005) with glucose as the standard. After purification, the EPS contained $\sim 99 \%$ carbohydrates, $\sim 1 \%$ protein and undetectable amounts of DNA. The monosaccharide composition of WH15EPS was previously characterized (Kielak et al., 2017) and comprises xylose (41.8\%), mannose $(10.25 \%)$, glucose $(13.55 \%)$, galactose $(26.12 \%)$, rhamnose $(0.065 \%)$, glucuronic acid (8.09) and galacturonic acid (0.085\%).

\subsection{Stable isotope probing (SIP) incubation}

One milliliter of Milli-Q sterile water was added to the freeze-dried EPS immediately before inoculation in soil to facilitate a homogeneous distribution within the soil. Five grams (wet weight) of soil with $0.05 \%$ (wt/wt) WH15EPS (labeled and unlabeled controls) or without EPS were added to a $120-\mathrm{ml}$ bottle, which was sealed with a butyl rubber stopper and incubated at room temperature $\left(22{ }^{\circ} \mathrm{C}\right)$ in the dark at $70 \%$ waterholding capacity (WHC). Each treatment (labeled EPS, unlabeled EPS and control without EPS) had six replicates. All vials were uncapped and aired every 4 days to maintain oxic conditions and prevent ${ }^{13} \mathrm{CO}_{2}$ crossfeeding. The vial headspace $\mathrm{CO}_{2}$ was monitored daily via gas chromatography (GC) (Trace GC Ultra, Thermo Fisher Scientific, Massachusetts, USA). For incubations with $\left[{ }^{13} \mathrm{C}\right]$-labeled EPS, the headspace $\mathrm{CO}_{2}$ ${ }^{13} \mathrm{C} /{ }^{12} \mathrm{C}$ ratio was monitored via GC combustion isotope ratio mass spectrometry (GC/C/IRMS) (GC IsoLink II TM IRMS System, Thermo Fisher Scientific, Massachusetts, USA). For DNA extraction, $0.5 \mathrm{~g}$ was sampled from the vials on days 8,24 and 35 , which corresponded to 10 , 25 and $43 \%{ }^{13} \mathrm{CO}_{2}$ headspace enrichment, respectively. The differences in $\mathrm{CO}_{2}$ emissions on the different days were analyzed by analysis of variance (ANOVA one-way repeated measurements) using mixed-effects models ('lmerTest' (Kuznetsova et al., 2017) and 'psycho' (Makowski, 2018) packages in $\mathrm{R}$ ).

\subsection{DNA extraction and fractionation}

DNA was extracted from $250 \mathrm{mg}$ of soil with or without ${ }^{13} \mathrm{C}$-labeled/ unlabeled substrates with the PowerSoil ${ }^{\circledR}$ DNA Isolation Kit (MO BIO Laboratories, Inc) according to the manufacturer's instructions. DNA was quantified by a spectrophotometer (NanoDrop ${ }^{\mathrm{TM}}$ 2000, Thermo Fisher Scientific, Massachusetts, USA) and visualized by $1.0 \%$ agarose gel electrophoresis and ethidium bromide staining. For gradient fractionation, $2 \mu \mathrm{g}$ of DNA was combined with $\mathrm{CsCl}\left(1.72 \mathrm{~g} \mathrm{ml}^{-1}\right)$ and gradient buffer (100 mM Tris-HCl pH 8.0, $100 \mathrm{mM} \mathrm{KCl,} 1 \mathrm{mM}$ EDTA) in an ultracentrifugation tube (PA UltraCrimp $1.8 \mathrm{ml}$, ThermoFisher Scientific, Massachusetts, USA)(Neufeld et al., 2007) and ultracentrifuged at $125,395 \times g$ (Discovery $120 \mathrm{SE}$ ultracentrifuge, ThermoFisher 
Scientific, Massachusetts, USA) under vacuum at $20{ }^{\circ} \mathrm{C}$ for $65 \mathrm{~h}$. Gradient fractionation resulted in 18 DNA fractions of approximately $100 \mu \mathrm{l}$ each. The density of each fraction was measured with a refractometer (AR200, Reichert Technologies, New York, USA) to confirm gradient formation. DNA was precipitated from the $\mathrm{CsCl}$ with polyethylene glycol solution (30\% PEG6000, $1.6 \mathrm{M} \mathrm{NaCl})$ and glycogen $(20$ $\mu \mathrm{g} / \mu \mathrm{l})$, washed with $70 \%$ ethanol, and eluted in $30 \mu \mathrm{l}$ of $10 \mathrm{mM}$ Tris- $\mathrm{HCl}$ buffer, $\mathrm{pH}$ 8.0. The DNA concentration of each fraction was determined in a Qubit 4 Fluorometer (ThermoFisher Scientific, Massachusetts, USA) using a Quant-iT ${ }^{\mathrm{TM}}$ dsDNA HS Assay Kit (Invitrogen, Carlsbad, California, USA). The unlabeled substrate incubations were used as controls to determine the expected position of labeled soil DNA in the $\mathrm{CsCl}$ density gradients. "Heavy" fractions were chosen at densities at which little or no total DNA was detected in the control sample fractions.

\subsection{PCR, sequencing and sequence processing of $16 S$ rRNA gene and ITS} data

Amplicon library preparation and high-throughput sequencing were performed using the "heavy" DNA fractions from samples belonging to the labeled EPS treatment pooled within each sample replicate as well as the total DNA of both the amended and unamended controls. The V3-V4 region of the $16 \mathrm{~S}$ rRNA gene and the internal transcribed spacer 1 (ITS1) region were targeted for bacteria and fungi, respectively. For bacteria, the V3-V4 region of $16 \mathrm{~S}$ rRNA gene was targeted by using $515 \mathrm{~F}\left(5^{\prime}\right.$ GTGCCAGCMGCCGCGGTAA-3') as forward primer and 806R (5'GGACTACHVGGGTWTCTAAT-3') (Bergmann et al., 2011) as reverse primer. For fungi, the Internal Transcribed Spacer 1 (ITS1) region was targeted by using primers ITS1F (5'-CTTGGTCATTTAGAGGAAGTAA-3') and ITS2 (5'-GCTGCGTTCTTCATCGATGC-3') (White et al., 1990). The amplification steps and Illumina MiSeq PE250 sequencing were performed at McGill University and Génome Québec Innovation Centre (Montréal, Québec, Canada). The sequences were deposited in the European Nucleotide Archive (ENA; https://www.ebi.ac.uk/ena) under the accession number PRJEB29719.

\subsection{Processing and statistical analyses of $16 S$ rRNA gene and ITS data}

Raw sequencing data were processed through Hydra pipeline version 1.3.3 (Hollander, 2017) implemented in Snakemake (Koster and Rahmann, 2012). Reads were first quality filtered, by trimming adapters sequences and removing PhiX contaminants, using BBDuk2 from the BBMap tool suite (Bushnell, 2015). Paired-ends were merged using the fastq_mergepairs option from vsearch (Rognes et al., 2015). The ITS1 region was extracted from ITS sequence dataset using ITSx version 1.011 (Bengtsson-Palme et al., 2013). Next, vsearch was employed to cluster all reads into OTUs through the UPARSE strategy by dereplication, sorting by abundance with at least two sequences and clustering using the UCLUST smallmem algorithm (Edgar, 2010). Chimeriq sequences were detected and removed using the UCHIME algorithm in de-novo mode (Edgar et al., 2011) implemented in VSEARCH. Before dereplication step, all reads were mapped to OTUs with the usearch_global method implemented in VSEARCH to generate an OTU table and converted to BIOM-Format (McDonald et al., 2012). For 16S rRNA sequences, the taxonomic information for each OTU was then added to the BIOM file by aligning the sequences to the SILVA database (release 128) (McDonald et al., 2012) using SINA classifier (Pruesse et al., 2012). For ITS sequences, the taxonomic information was added to the BIOM file by running the RDP Classifier re-trained on the UNITE database release 7.2 (Kõljalg et al., 2013). Fungal OTUs were assigned to functional guilds using the annotation tool FUNGuild (Nguyen et al., 2016). For assignment at the OTU, genus and phylum levels, 97\%, 95\% and 75\% sequence similarity were used as thresholds, respectively (Webster et al., 2009).

\subsection{Multivariate analyses of $16 S$ rRNA gene and ITS data}

Statistical analyses were performed in RStudio version 1.1.423 running $\mathrm{R}$ version 3.4.4 ( $\mathrm{R}$ Core Team, 2015). OTUs with less than 2 counts across all samples and chloroplast and mitochondrial sequences were discarded. Prior to alpha and beta diversity analyses, the data were rarefied to the size of the smallest sample (4243 reads for the 16S rRNA gene and 7797 for ITS region data). The 'Phyloseq' package (McMurdie and Holmes, 2013) was used to calculate the number of observed OTUs, Shannon and Inverse Simpson diversity indices, and Chao1 and ACE diversity estimators. Significant differences in the estimators between treatments were evaluated through parametric and non-parametric tests, including ANOVA, Kruskal-Wallis and Tukey's HSD tests (package 'agricolae' (Mendiburu, 2017)). Bray-Curtis distance matrices constructed using the rarefied datasets were used for principal coordinate analysis (PCoA) using the capscale function from the 'vegan' package (v. 2.4.6 (Oksanen et al., 2018)). Group dissimilarities were tested by permutational multivariate analysis of variance (PERMANOVA) using the function Adonis from the 'vegan' package. To compare the structures of the bacterial and fungal communities within treatments, co-inertia (COIA) analysis of the Hellinger transformed datasets (Legendre and Gallagher, 2001) was performed using the function coinertia of the package 'ade4' (Dray and Dufour, 2007) as described by Schlemper et al. (2017). For this analysis, OTUs with less than 15 counts were excluded, and then grouped at genus level. RV. test function was applied to run Monte-Carlo test for COIA, with 999 permutations. As a result, COIA plots display arrows that illustrate the strength of the relationships between bacterial and fungal communities, which is inversely proportional to length of the arrows. In addition, arrows pointing to the same direction suggest associations between treatments. Potential interactions between bacterial and fungal genera within treatments were investigated via SparCC correlation coefficients, with default parameters and 100 bootstraps (Friedman and Alm, 2012). Networks were built with significant correlations $(\mathrm{P}<0.05)$ at $|\mathrm{r}|>0.75$, and co-occurrence was visualized by Cytoscape (Shannon, 2003) and Gephi version 0.9.2 (https://gephi.org/). Topological parameters (numbers of nodes and edges and node degree number) were calculated using the network analyzer tool (Doncheva et al., 2012) pre-installed in Cytoscape. Other plots were generated using 'ggplot2' (Wickham, 2016) and the plot function in R.

\section{Results}

\section{1. $\mathrm{CO}_{2}$ measurements}

The $\mathrm{CO}_{2}$ emissions of the microcosms were $7500 \mathrm{ppm} \mathrm{CO}_{2}$ /day initially and progressively decreased during incubation. Average $\mathrm{CO}_{2}$ emissions were 1.3 times higher in the EPS-amended samples than in the unamended controls. At the end of the incubation, the EPS-amended microcosms $\mathrm{CO}_{2}$ emissions were 1.9 times higher than that of unamended controls. Headspace ${ }^{13} \mathrm{CO}_{2}$ enrichment increased throughout the incubation period, reaching $43 \%$ of the headspace in the labeled samples at day 35 (Fig. 1). The differences in $\mathrm{CO}_{2}$ emissions between treatments and P-values are shown in Table 1.

\subsection{Gradient fractionation}

The density profiles of the DNA extracted from soils incubated with ${ }^{13} \mathrm{C}$-EPS exhibited small changes compared with those of the control DNA from the ${ }^{12} \mathrm{C}$-EPS incubations (Fig. S1). Among the 6 replicates, two from day 8 (L2D8 and L6D8) had "heavy" DNA in higher-density fractions, probably due to variations in the $\mathrm{CsCl}$ density centrifugation.

\subsection{Sequencing and alpha diversity}

High-throughput sequencing generated 1,250,548 and 828,045 


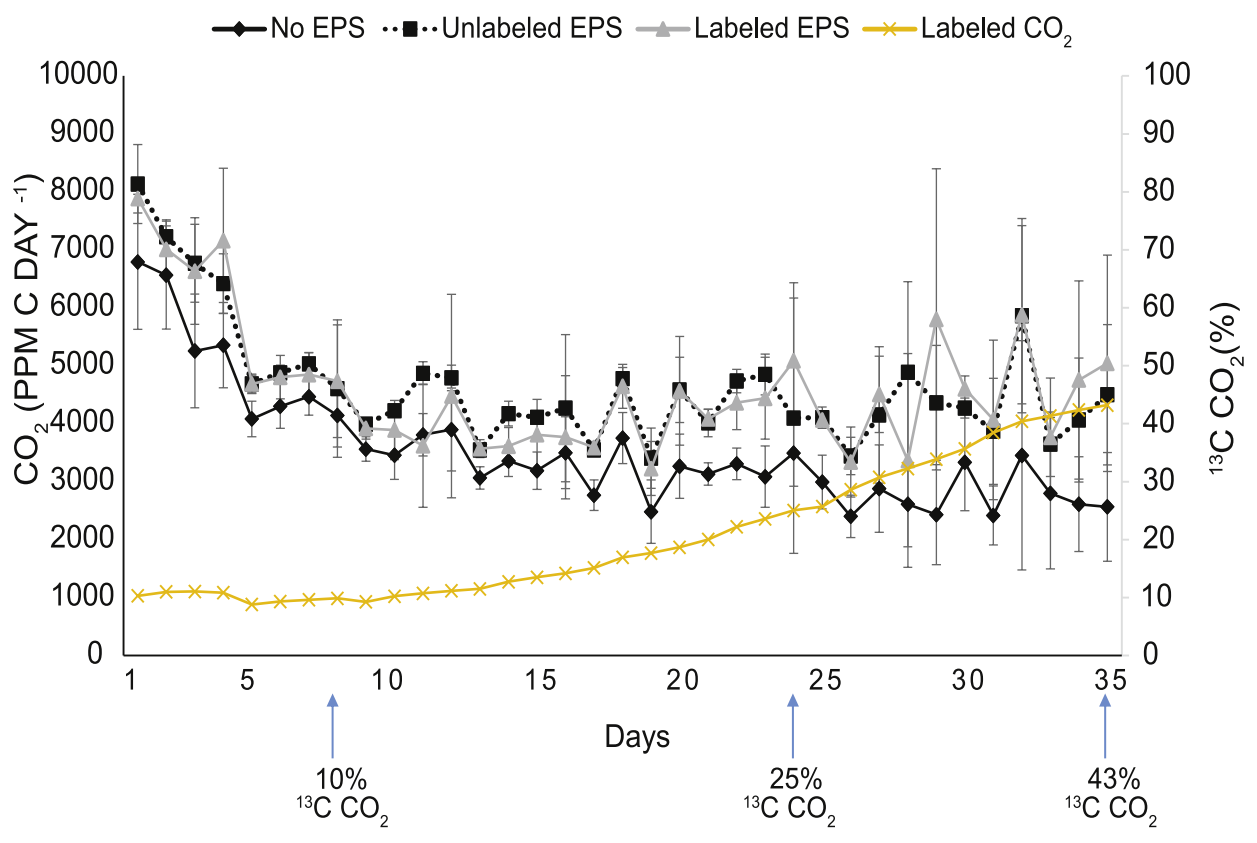

Fig. 1. $\mathrm{CO}_{2}$ emission. $\mathrm{CO}_{2}$ production during total incubation period. No EPS: control without EPS; Unlabeled EPS: control containing ${ }^{12} \mathrm{C}$-EPS; Labeled EPS: incubation with ${ }^{13} \mathrm{C}$-EPS; Labeled $\mathrm{CO}_{2}$ percentage: ${ }^{13} \mathrm{CO}_{2}$ emitted during ${ }^{13} \mathrm{C}$-EPS sample incubation; water: days when samples were hydrated; air: days when samples were aired. Error bars represent standard error of the mean $(n=6)$.

Table 1

Contrast between $\mathrm{CO}_{2}$ emission curves and statistical P-values.

\begin{tabular}{lll}
\hline Contrast & Difference & P-value \\
\hline Unlabeled EPS -Control & 1094.9 & 0.01 \\
Labeled EPS-Control & 1058.1 & 0.02 \\
Unlabeled EPS - Labeled EPS & -36.8 & 0.99 \\
\hline
\end{tabular}

good-quality sequences for the bacterial 16S rRNA gene and fungal ITS region, respectively. Good's coverage (Table 2) indicated that the number of sequence reads covered $96.2 \%-98.4 \%$ of the bacterial diversity and $99.1-99.9 \%$ of the fungal diversity in the samples at the OTU level (3\% dissimilarity). Overall, for the $16 \mathrm{~S}$ rRNA samples, the "heavy" fraction samples at all time points had significantly lower richness and diversity values than the unamended and ${ }^{12} \mathrm{C}$-EPS-amended controls. Moreover, the ${ }^{12} \mathrm{C}$-EPS-amended samples had lower richness and diversity values than the unamended samples (Fig. S2).

Similar to the 16S rRNA gene samples, the richness and diversity values of the ITS region were lower in the "heavy" fraction samples compared with the controls. This tendency was most obvious at days 24 and 35 , whereas at day 8 , the richness of the "heavy" fraction was not

Table 2

Good's coverage for 16S rRNA gene and ITS region sequences within treatments.

\begin{tabular}{|c|c|c|c|c|c|}
\hline \multicolumn{3}{|c|}{ 16S rRNA gene sequences } & \multicolumn{3}{|c|}{ ITS region sequences } \\
\hline Treatment & Day & $\begin{array}{l}\text { Good's } \\
\text { coverage }\end{array}$ & Treatment & Day & $\begin{array}{l}\text { Good's } \\
\text { coverage }\end{array}$ \\
\hline Control & 8 & 96.2 & Control & 8 & 99.3 \\
\hline Unlabeled EPS & 8 & 96.4 & Unlabeled EPS & 8 & 99.2 \\
\hline $\begin{array}{l}\text { "Heavy" } \\
\text { fraction }\end{array}$ & 8 & 97.4 & $\begin{array}{l}\text { "Heavy" } \\
\text { fraction }\end{array}$ & 8 & 99.6 \\
\hline Control & 24 & 96.3 & Control & 24 & 99.2 \\
\hline Unlabeled EPS & 24 & 96.9 & Unlabeled EPS & 24 & 99.3 \\
\hline $\begin{array}{l}\text { "Heavy" } \\
\text { fraction }\end{array}$ & 24 & 98.4 & $\begin{array}{l}\text { "Heavy" } \\
\text { fraction }\end{array}$ & 24 & 99.9 \\
\hline Control & 35 & 96.3 & Control & 35 & 99.0 \\
\hline Unlabeled EPS & 35 & 97.0 & Unlabeled EPS & 35 & 99.4 \\
\hline $\begin{array}{l}\text { "Heavy" } \\
\text { fraction }\end{array}$ & 35 & 98.3 & $\begin{array}{l}\text { "Heavy" } \\
\text { fraction }\end{array}$ & 35 & 99.8 \\
\hline
\end{tabular}

significantly different from that of the controls (Fig. S3).

\subsection{Community structures}

PERMANOVA showed that the bacterial communities differed significantly ( $\mathrm{P}=1.00 \mathrm{e}-04$ ) between the different treatments, days and treatment:day interactions, with the "heavy" fractions on days 24 and 35 clustering separately from the controls and the day 8 "heavy" fraction in the PCoA plot (Fig. 2a). The bacterial communities clearly clustered according to treatments and days, with the first two axes of the PCoA explaining $70.5 \%$ of the variation.

The fungal community patterns at different time points were less clear than those of the bacterial community. The fungal communities were more spread throughout the PCoA plot (Fig. 2b). However, the heavy fractions on days 24 and 35 also clustered separately from the control samples and the day 8 "heavy" fraction. PERMANOVA indicated significant differences ( $\mathrm{P}$ value $=9.999 \mathrm{e}-05$ ) between treatments, days and treatment:day interactions, with the first two axes of the PCoA explaining $27.8 \%$ of the variation among samples.

Co-inertia analysis revealed significant co-structures between the bacterial and fungal communities for all treatments $(P<0.5)$. The first 2 co-inertia axes explained $80.4 \%$ ("heavy" fraction), $61.8 \%$ (EPS amended control) and $59.9 \%$ (unamended control) (cumulative projected inertia) of the total variance in the bacterial-fungal assessments (Fig. 2cde). In addition, the bacterial and fungal groups at the genus level that contributed most to the co-variance between samples were identified, which reflected the differences in abundances among time points (Fig. S4).

\subsection{Bacterial community beta diversity}

Twenty-two groups at the phylum level were observed in all samples. At day 8, the most abundant phylum in all samples was Proteobacteria (32.01\%-39.7\%) (Fig. S5a). At day 24, the separation between microbial communities observed in the PCoA analysis became evident. The most abundant phylum was Planctomycetes in the "heavy" fraction (59.79\%) but Proteobacteria in both control treatments $(28.56 \%$ $31.23 \%$ ) (Fig. S5a). At day 35, Planctomycetes (60.79\%) was still the 

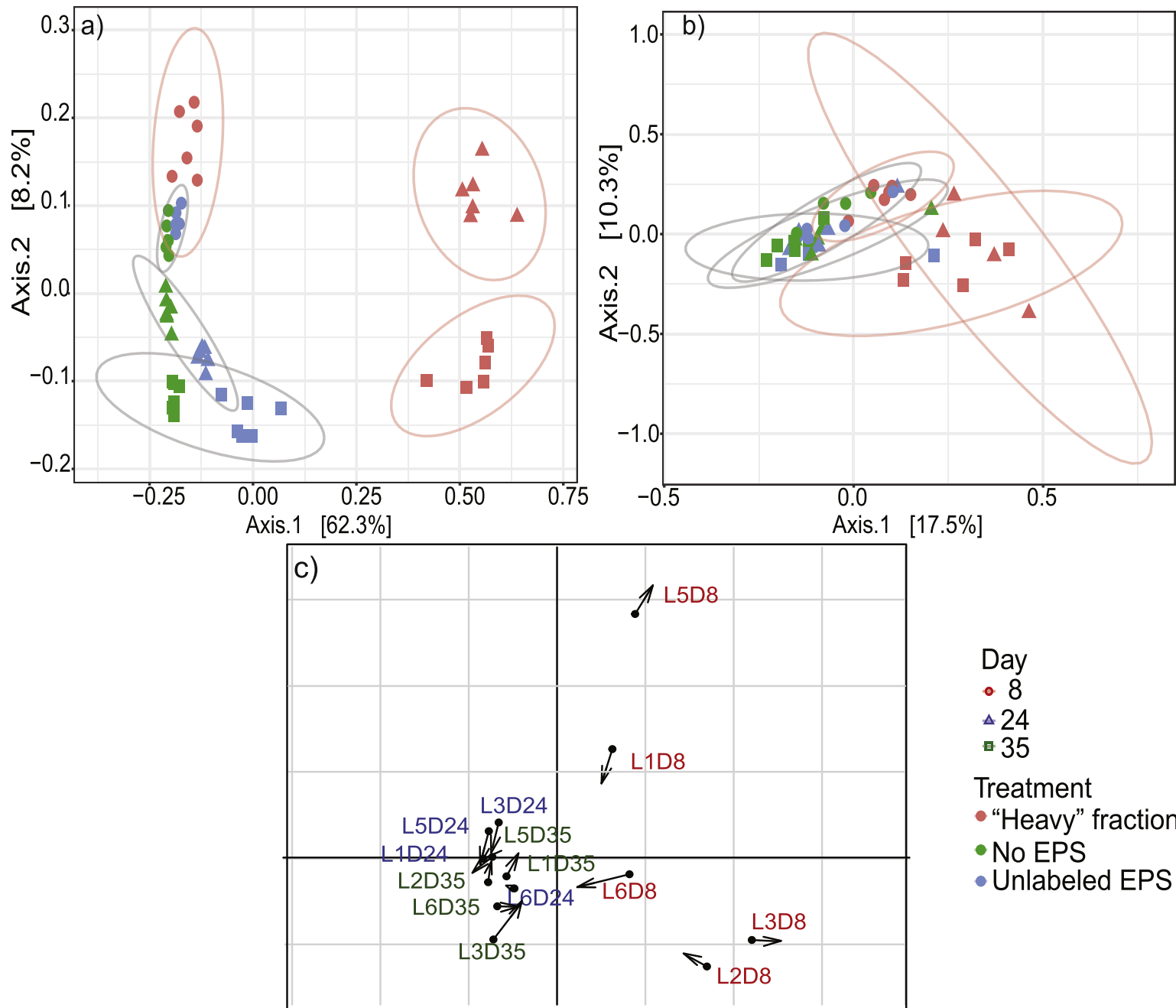

Day

- 8

$\triangle 24$

$\because 35$

Treatment

- "Heavy" fraction

- No EPS

- Unlabeled EPS

Bacteria-Fungi COIA (RV.test $=0.834, \mathrm{P}=0.001$ )
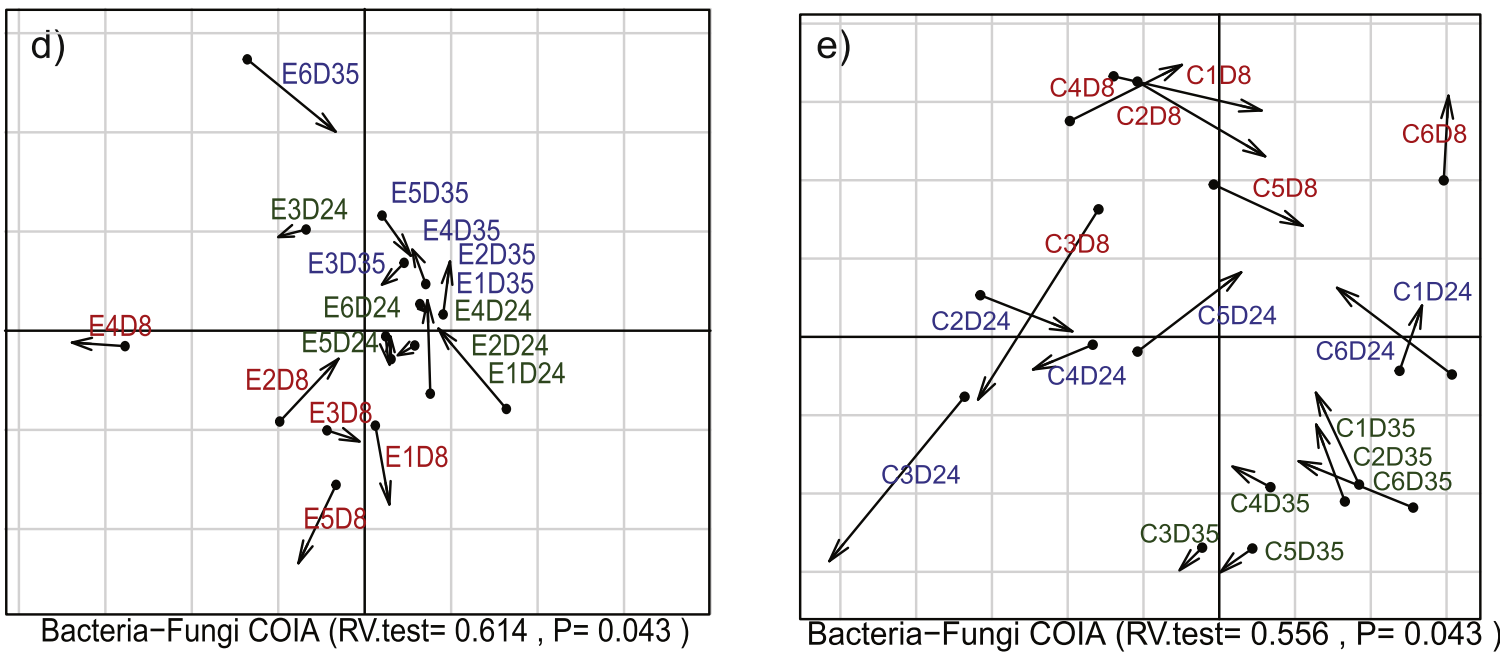

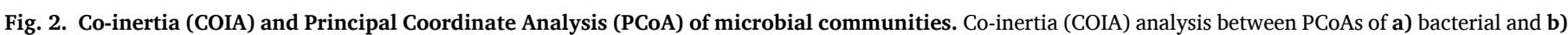

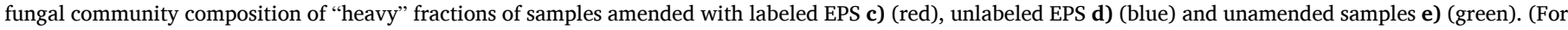
interpretation of the references to color in this figure legend, the reader is referred to the Web version of this article.)

most abundant phylum in the "heavy" fraction samples (Fig. S5a), and Proteobacteria (25.65\%-25.74\%) remained the most abundant phylum in the controls.

At the genus level, 220 groups were found in all samples. At day 8 , unclassified Pedosphaeraceae was the most abundant group in the "heavy" fraction and the unamended control (12.34\% and $13.04 \%$, respectively). In the ${ }^{12} \mathrm{C}$-EPS-amended treatment, the most abundant genus was Rhodanobacter (12.12\%) (Fig. 3a).

At day 24, Singulisphaera was the most abundant genus in the "heavy" fraction samples (27.79\%) but represented only approximately 
a)
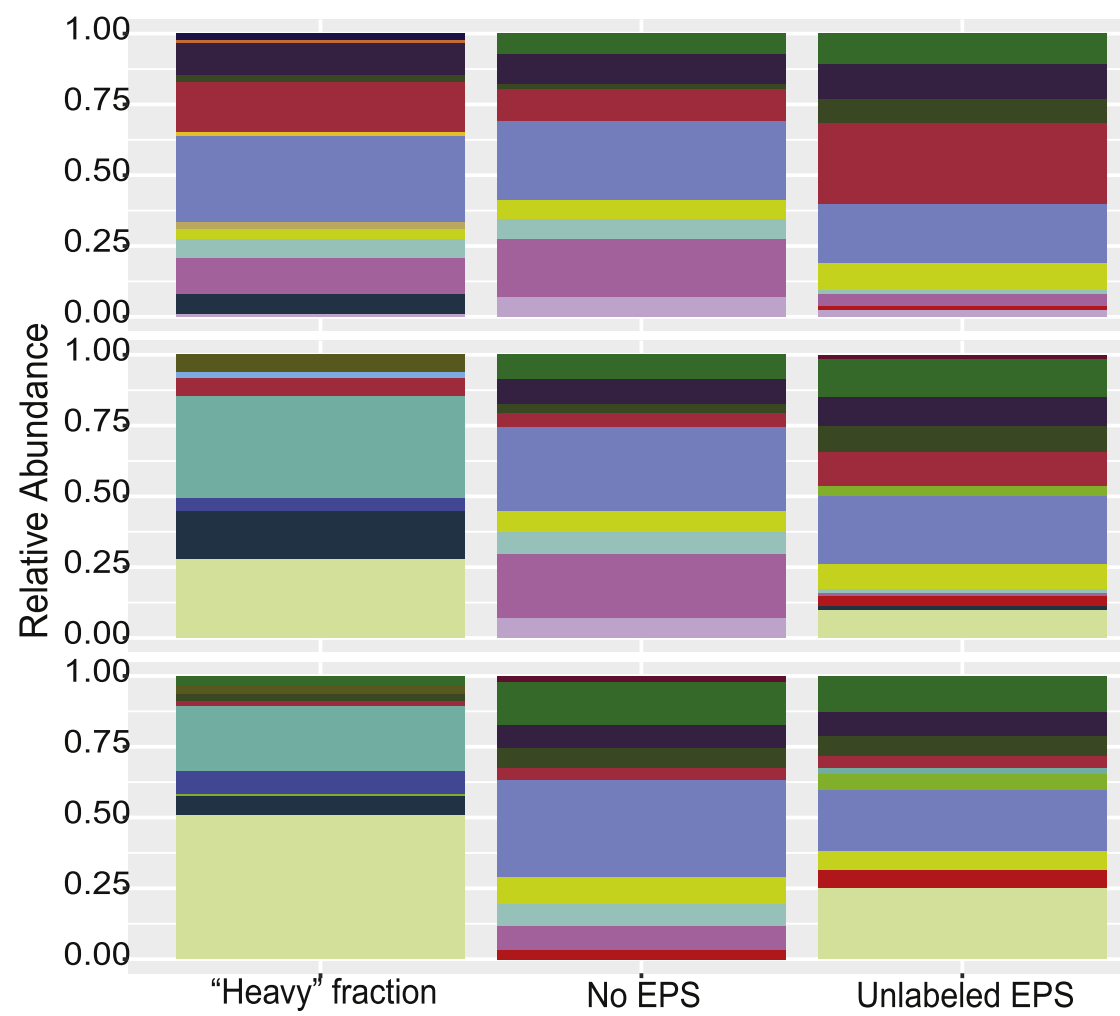

$\infty$

$\infty$

Acidibacter

Acidothermus

Aliterella CENA595

Candidatus Nostocoida

Edaphobacter

Gemmata

Granulicella

Occallatibacter

Rhodanobacter

$\sim$ Singulisphaera

$\stackrel{x}{n}$

Unc. Acetobacteraceae

Unc. Armatimonadales

Unc. KF-JG30-C25

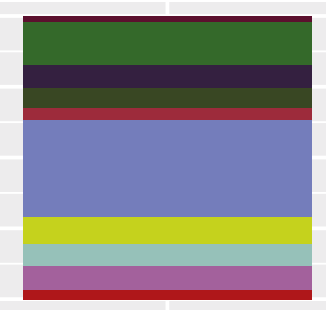

No ĖPS

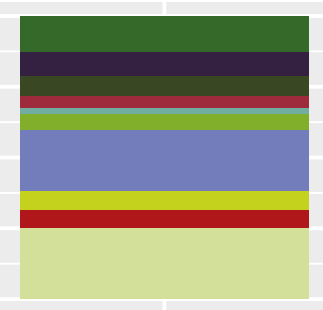

Unc. Pedosphaeraceae

Unc. Rhodanobacteraceae

Unc. Acidobacteria Gp 2

Unc. WD2101

$\omega$

Unc. WPS-2

b)
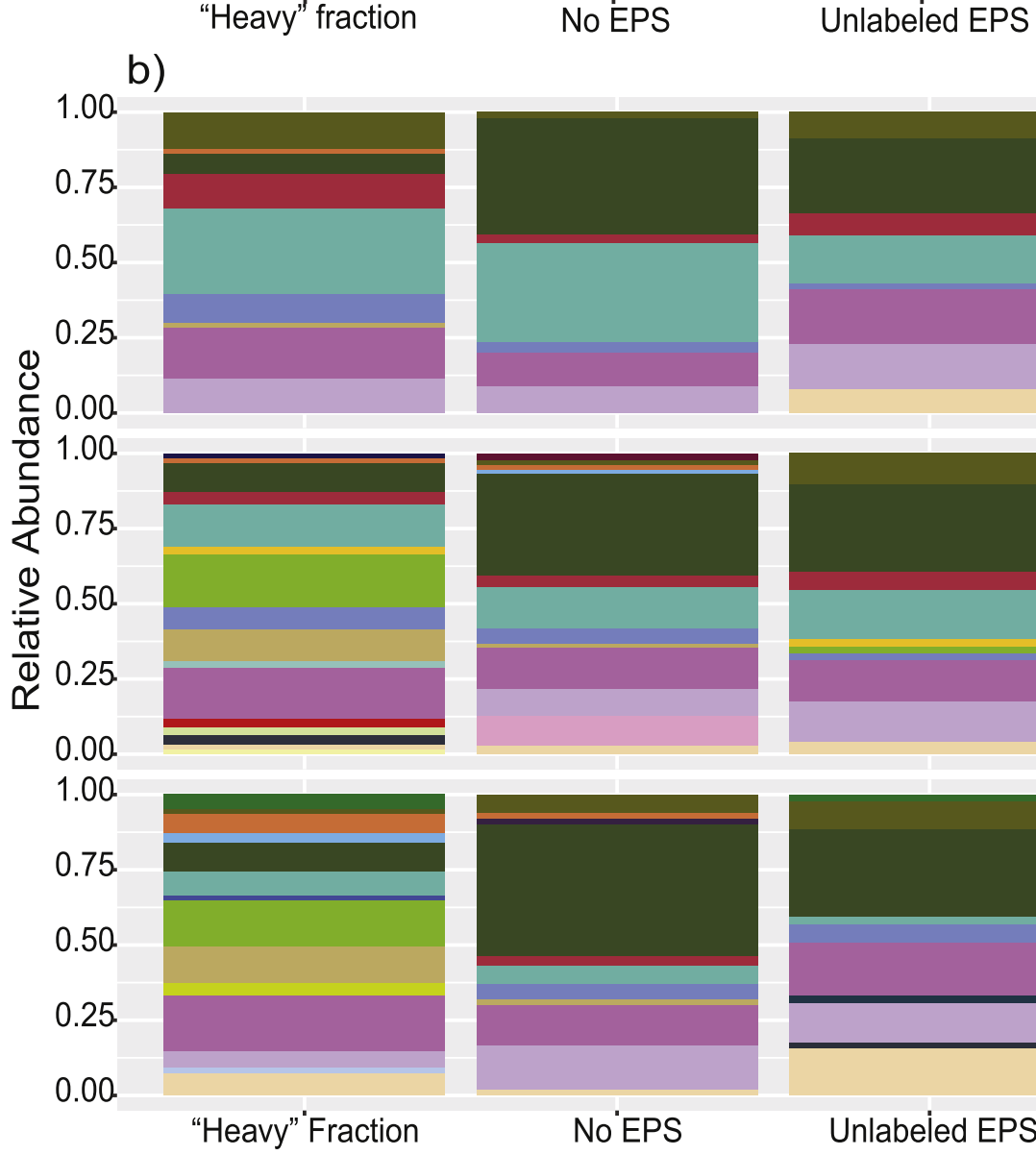

Unc Acidobacteria Gp1

Unc. Methylacidiphilaceae

Unc. Pirellulaceae

Unc. Xanthobacteraceae

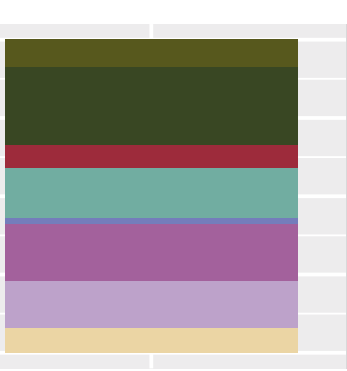

Group
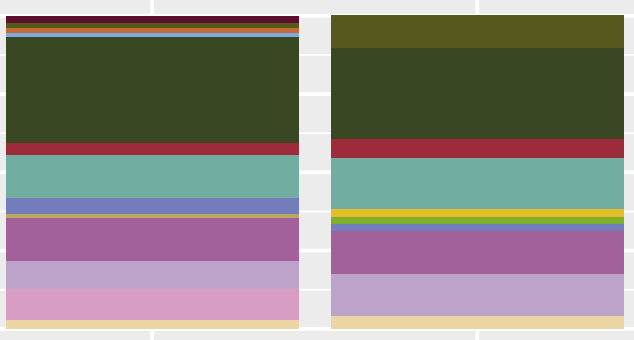

$\infty$

Amaurodon Archaeorhizomyces

Baeospora

Humicola

Jaapia

Lactarius

Luellia

Mortierella

Russula

Scleroderma

Tolypocladium

Trechispora

Trichoderma

$\stackrel{N}{\perp}$

Unc. Ascomycota

Unc. Agaricomycetes

Unc. Bionectriaceae

Unc. Botryosphaeriales

Unc. fungi

Unc. GS11

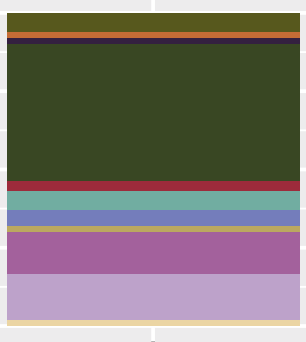

No EPS

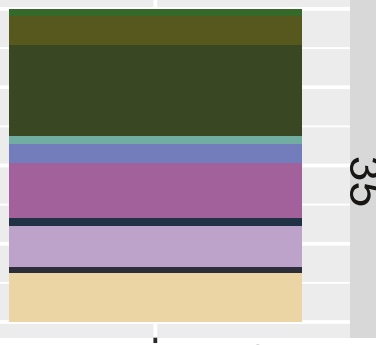

Unc. Helotiales

Unc. Lecaronomycetes

Unc. Mortierellales

$\omega$ Unc. Nectriaceae

Unc. Rozellomycota

Unc. Trechisporales

Unc. Tremellomycetes

Unc. Trichosporonaceae

\section{Treatment}

Fig. 3. Relative abundance of microbial genera. Relative abundance of a) bacterial and b) fungal groups at genus level in "heavy" fraction, EPS amended (Unlabeled EPS) and unamended (No EPS) controls at all time points (days 8, 24, 35). Only genera with $>3 \%$ abundance are shown. 
$1.07-1.28 \%$ of the sequences in the control treatments. In both control treatments, unclassified Pedosphaeraceae (10.91\%-14.36\%) was the predominant group (Fig. 3a).

At day 35, uncultured Pirellulaceae (36.21\%) was the most abundant group in the "heavy" fraction, followed by Singulisphaera (16.22\%). In the unamended control, the most abundant group was unclassified Pedosphaeraceae (16.52\%), while in the amended control, the predominant group was uncultured Pirellulaceae (12.14\%) (Fig. 3a).

\subsection{Fungal community beta diversity}

At the phylum level, 11 groups were observed in all samples. At days 8 and 24, Basidiomycota was the most abundant phylum in all samples (35.92\%-43.16\%) (Fig. S5b). At day 35, the predominant group was Basidiomycota in the "heavy" fraction samples (38.7\%) but Mortierellomycota in the unamended control (33.36\%). In the ${ }^{12} \mathrm{C}$-EPS amended control samples, Ascomycota (33.87\%) was the most abundant phylum (Fig. S5b).

At the genus level, 282 groups were observed in all samples. At day 8, the most abundant genus was Scleroderma in the "heavy" fractions (18.02\%) but Mortierella in both control treatments (22.39\%) (Fig. 3b). At day 24, Trichoderma (15.67\%) was the most abundant genus in the "heavy" fraction samples. In both control treatments, Mortierella was the most abundant genus (15.31\%-21\%) (Fig. 3b). At day 35, unclassified fungi in the "heavy" fraction samples increased and were the most abundant group (15.21\%), followed by Trichoderma (12.69\%). Mortierella remained the most abundant genus in both control treatments (15.63\%-24.96\%) (Fig. 3b). Analysis with FUNGuild assigned guilds to approximately $60 \%$ of the OTUs. The guild assignments demonstrated that all treatments, regardless of time point, were dominated by ectomycorrhizal fungi, soil saprotrophs and undefined saprotrophs (Fig. S6).

\subsection{Co-occurrence network analyses}

\subsubsection{Heavy fraction}

The co-occurrence network of "heavy" fraction samples (Fig. 4a) incorporated 59 nodes and 377 edges, with 51 bacterial nodes and 8 fungal nodes. At the genus level, 2 bacterial groups had connections with fungi, and 2 fungal groups were connected to bacteria. In total, 139 of the 377 connections were negative. The network contained several densely connected nodes, with 15 nodes having more than 20 neighbors each. The group with the highest number of connections was a Planctomycetes group, unclassified Gemmataceae (31 neighbors). Other groups with high connectivity were uncultured Solirubrobacteraceae (30 neighbors), unclassified Armatimonadales and Acidothermus (29 neighbors each). We also analyzed the bacterial genus identified as the most abundant in the "heavy" fractions, Singulisphaera, as well as the WH15EPS producer genus, Granulicella. In this treatment, Singulisphaera and Granulicella had 23 and 21 neighbors, respectively. Both genera had mainly positive connections (20 for Singulisphaera and 12 for Granulicella). No fungal group was connected to Singulisphaera, which was mainly connected to Planctomycetes and Actinobacteria (Fig. 4d). The groups associated with Singulisphaera and Granulicella are described in Supplementary Table S1. No strong associations were detected between Granulicella and Singulisphaera. The most abundant fungal genus, Trichoderma, did not have any strong correlation.

\subsection{2. ${ }^{12}$ C-EPS-amended control}

The network for the 12C-EPS-amended control (Fig. 4b) contained 29 nodes and 46 edges, with 18 bacterial nodes and 11 fungal nodes. Two bacterial groups were connected to fungi, and 3 fungal groups were connected to bacteria. No group had more than 10 neighbors, the maximum number of neighbors of a node in this network. Singulisphaera and uncultured Pirellulaceae had the highest number of neighbors (10), followed by Rhodanobacter, Unclassified KF-JG30-C25 and uncultured Solirubrobacteraceae, with 6 neighbors each. In this treatment,
Granulicella did not have any strong connections. Singulisphaera had only 2 negative connections, with Dyella and Rhodanobacter (Fig. 4e). The associations of Singulisphaera are described in Supplementary Table S2.

\subsubsection{Unamended control}

The network for the unamended control (Fig. 4c) possessed 54 nodes and 66 edges, with 41 bacterial and 13 fungal nodes. Among all associations, 2 bacterial groups were connected to fungi, and 3 fungal groups were connected to bacteria. No groups had more than 10 neighbors. Genus Burkholderia-Caballeronia-Paraburkholderia had the highest amount of neighbors (10), followed by Conexibacter (7 neighbors), Dyella and uncultured Acidobacteriaceae subgroup 1. (6 neighbors each). Singulisphaera had only one positive connection to unclassified Isosphaeraceae (Fig. 4f). Granulicella did not have any strong association.

\section{Discussion}

Here, we investigated the assimilation of EPS produced by Granulicella sp. strain WH15, a member of Acidobacteria. The ${ }^{13} \mathrm{C}$-labeled biopolymer was applied to organic topsoil samples, and highthroughput sequencing of the bacterial 16S rRNA gene and fungal ITS1 region identified the main EPS metabolizers. To increase the probability of finding true interactions, the organic topsoil samples were collected from the same forest site where Granulicella sp. strain WH15 was isolated (Valášková et al., 2009).

Although the degradation of bacterial-produced biopolymers has been explored previously (cellulose produced by the bacterium Gluconacetobacter xylinus (Verastegui et al., 2014; Wang et al., 2015), indican from Beijerinckia indica (Wang et al., 2015), and fructan from Lactobacillus reuteri (van Bueren et al., 2015)), the metabolism of EPS produced by Acidobacteria and its ecological implications have not been investigated. The addition of purified WH15EPS to the organic topsoil increased microbial activity compared with the unamended control, as measured by $\mathrm{CO}_{2}$ respiration. The incorporation of the labeled EPS was confirmed by the increase in ${ }^{13} \mathrm{CO}_{2}$ release during incubation, which ranged from $10 \%$ to $43 \%$ of total headspace $\mathrm{CO}_{2}$. The amount of ${ }^{13} \mathrm{CO}_{2}$ emitted varies according to the complexity of the substrate used for incubation and the capacity of the microbial community to degrade it (Štursová et al., 2012). Although the labeled material was clearly incorporated, the amount of "heavy" DNA recovered was lower than that reported in other SIP studies (Zhang et al., 2016), likely due to the complexity of the substrate, a heteropolysaccharide composed of 7 different monosaccharides (Kielak et al., 2017), and competition with the carbon present in the litter material (approximately $50 \%$ of organic matter). Longer incubation times can improve the recovery of "heavy" DNA; however, a limitation of this strategy is that it also increases the possibility of cross-feeder enrichment (Verastegui et al., 2014).

\subsection{Alpha and beta diversity}

The alpha diversity indices of the bacterial communities in the "heavy" fractions indicated lower richness and diversity than the amended and unamended controls at all sampling points, reflecting the selection of microorganisms capable of metabolizing the added EPS, particularly at day 35 . These dynamics, however, were not as consistent for the fungal communities.

At day 8, the genus Rhodanobacter predominated in the EPSamended control; however, the group unclassified Pedosphaeraceae was the most abundant in the "heavy" fraction and in the unamended control. Rhodanobacter is a genus of the family Xanthomonadaceae (Proteobacteria) found in soils featuring decomposition of aromatic compounds (Nalin et al., 1999; Uhlik et al., 2012; Song et al., 2016) and forest litter (Štursová et al., 2012; Verastegui et al., 2014). Pedosphaeraceae (subdivision 3) is an uncharacterized family within the phylum Verrucomicrobia, which, like Acidobacteria, is widespread among terrestrial environments and has few cultivated representatives (Spring 

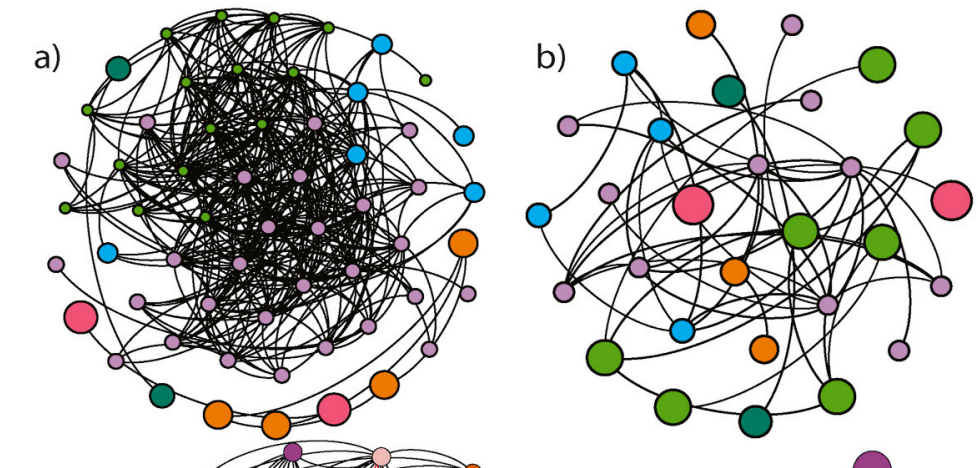

c)
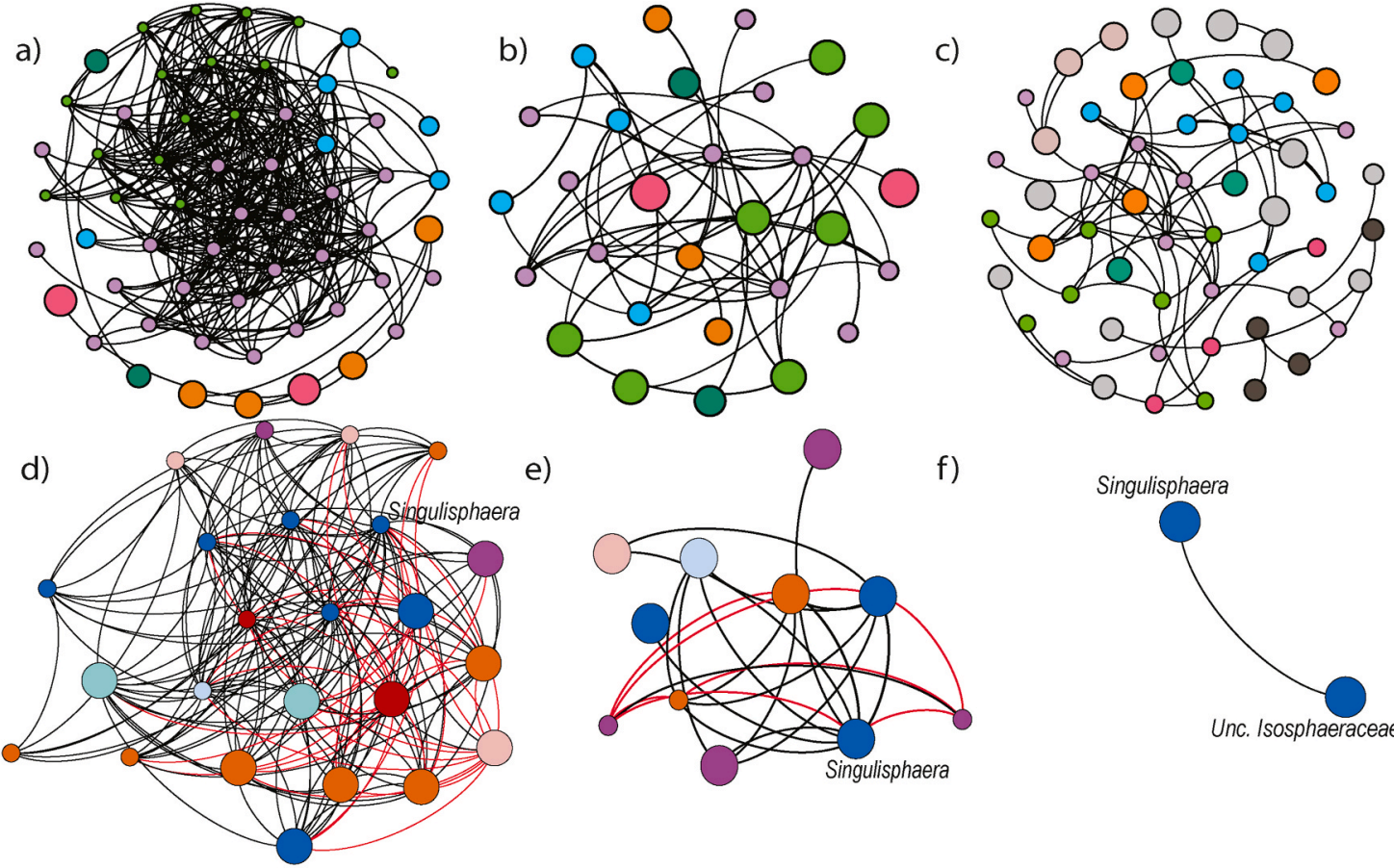

e)

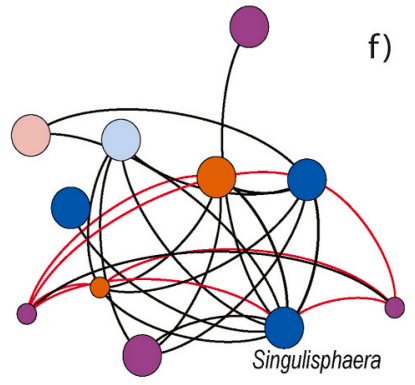

Singulisphaera

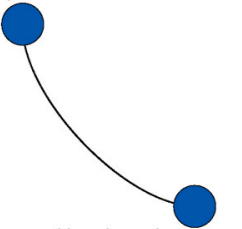

Unc. Isosphaeraceae

Acidobacteria $\bigcirc$ Actinobacteria $\bigcirc$ Armatimonadetes OPlanctomycetes OProteobacteria $\bigcirc$ Verrucomicrobia $\bigcirc$ Other

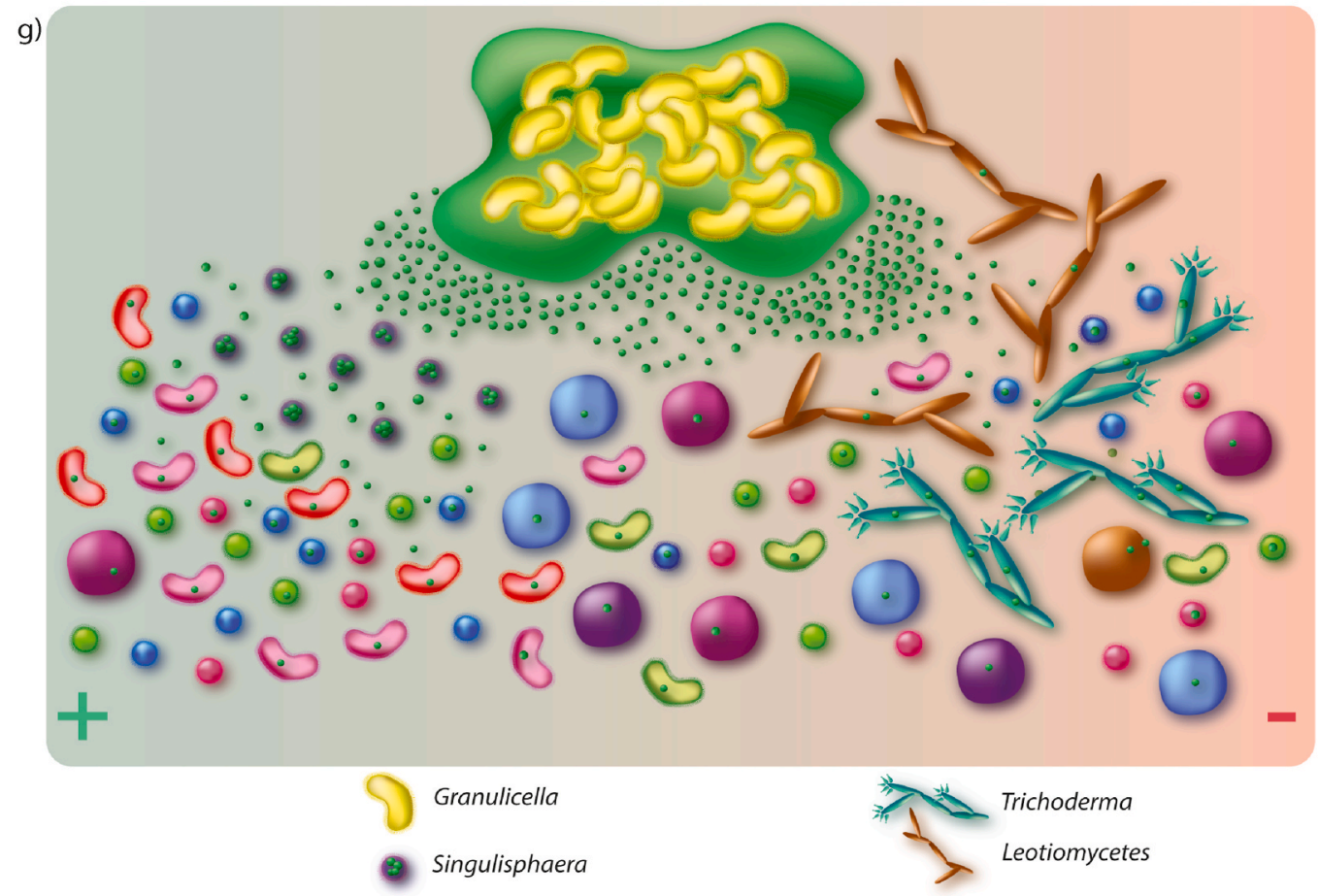

Fig. 4. Co-occurrence networks and conceptual framework of the interactions of microorganism during WH15EPS assimilation. Total networks for a) "heavy" fraction; b) Unlabeled EPS control; c) No EPS control (colors represent modularity classes); First neighbors of Singulisphaera genus in each treatment: d) "heavy" fraction; e) Unlabeled EPS control; f) No EPS control (network nodes are genera). The size of the nodes represents the number of neighbors. Black edges represent positive correlations; red edges represent negative correlations. The size of each node is proportional to the number of connections (degree); g) Cartoon illustrating simplified hypothetical relationships among microorganisms during the metabolization of the EPS produced by Granulicella sp strain WH15. Singulisphaera genus possessed negative (right (-)) correlations, as well as positive correlations (left $(+)$ ) with other bacterial genera. Negative associations suggest competition for the substrate, while positive associations suggest mutualism, via exchange of nutrients. (For interpretation of the references to color in this figure legend, the reader is referred to the Web version of this article.) 
et al., 2016).

Among the fungal communities, the genus Scleroderma was the most abundant in the "heavy" fractions and the second most dominant in the control samples after the genus Mortierella (which was also present in the heavy fraction). Scleroderma is a common, widespread ectomycorrhizal genus that produces macroscopic sporocarps in leaf litter, grass, bare soil or soil adjacent to forests (Jeffries, 1999). Mortierella is a root-colonizing endophytic fungus. Members of this globally distributed genus live as saprobes in soil on decaying organic material and dominate fungal communities in natural ecosystems (Johnson et al., 2018).

The significant differences in the bacterial and fungal communities among all treatments were most evident at the later time points, and therefore enrichment of any specific microbial genus in the "heavy" fraction could not be observed at day 8. Several genera and phyla appeared to incorporate WH15EPS, possibly due to the ready hydrolysis of the biopolymer by exoenzymes already present in the litter material at the time of incubation.

At day 24, in the bacterial communities, clear enrichment of the phylum Planctomycetes could be observed in the "heavy" fraction samples, reaching approximately $60 \%$ of the total sequence number, with the genus Singulisphaera as the most abundant. At day 35, the enrichment of Planctomycetes persisted, with the genus Singulisphaera among the predominant genera but overcome by another group of Planctomycetes, uncultured Pirellulaceae. At the genus level, the total abundance of Planctomycetes was distributed among Singulisphaera, Candidatus Nostocoida and unclassified groups such as uncultured Pirellulaceae and "WD2101 soil group". Planctomycetes inhabit a variety of environments, including aquatic and terrestrial habitats as well as extremely acidic environments (Schlesner, 1994; Wang et al., 2002; Ivanova and Dedysh, 2012; Faria et al., 2018). Planctomycetes are highly abundant and phylogenetically diverse, especially in acidic Sphagnum-dominated wetlands, where they can account for up to $54 \%$ of the total amount of 16S rRNA gene sequences. The $\mathrm{pH}$ in Sphagnum-dominated wetlands can be similar to our sampling location ( $\mathrm{pH} 3.0$ ), ranging from $\mathrm{pH} 3.7$ to 4.2 (Moore et al., 2015). Members of this phylum have unusual features, such as invaginations of the cytoplasmic membrane (Wiegand et al., 2018). Although the functions of Planctomycetes are not clearly understood, they possess a wide range of hydrolytic capabilities, which would explain the promotion of their enrichment by the metabolization of the complex heteropolysaccharide WH15EPS. Using a transcriptome approach, Ivanova et al. (2017a) observed that cellulose, xylan, pectin and chitin induced responses by different groups of Planctomycetes. The genus Singulisphaera responded significantly to pectin and xylan amendment. Members of the order Phycisphaerales and genus Zavarzinella also responded to xylan, while group WD2101 were responsive to cellulose and chitin. Another study by Ivanova et al. (2017b) further supported the high glycolytic potential of Planctomycetes. In that study, a comparative genomic analysis of 4 members of the family Isosphaeraceae, namely Isosphaera pallida, Singulisphaera acidiphila, Paludisphaera borealis and the uncharacterized strain SH-PL62S, identified several CAZYmes from major families (GH5, GH13, GH57) as well as potential $\alpha$-mannosidase, $\alpha$-rhamnosidase and glucuronyl hydrolase activities. In addition, several CAZYmes not affiliated with currently recognized enzymes were found, demonstrating that these bacteria have the ability to use a wide range of natural carbohydrates and undiscovered glycolytic potential. Furthermore, Singulisphaera acidiphila is capable of hydrolyzing several polysaccharides, such as laminarin, pectin, chondroitin sulfate, aesculin, pullulan, lichenan, xylan and gelatin (Kulichevskaya et al., 2008). Similar to the current study, Wang et al. (2015) reported enrichment of Planctomycetes by indican EPS of Beijerinckia indica. Indican is a biopolymer composed of glucuronic acid, glucose and glycerol-manno-heptose, indicating that Planctomycetes can decompose complex biopolymers.

Another group found in higher proportions in the "heavy" fractions at days 24 and 35 was uncultured Methylacidiphilaceae. This group belongs to the phylum Verrucomicrobia, which has few cultivated representatives but has been revealed to have hydrolytic capabilities in cultivation-independent studies. Martinez-Garcia et al. (2012) demonstrated that members of Verrucomicrobia have high hydrolytic potential and encode a wide spectrum of glycoside hydrolases, carbohydrate lyases and esterases in their genomes, indicating that they are well-equipped with enzymes for carbohydrate metabolism. Cardman et al. (2014) demonstrated that fluorescently labeled laminarin and xylan preferentially associated with Verrucomicrobia and proposed that this phylum is involved in polysaccharide hydrolysis.

Within the fungal communities, at day 24 , an increase in the proportions of the genus Trichoderma and groups of unclassified fungi was observed in the "heavy" fraction compared with both the amended and unamended controls. Trichoderma is a genus of filamentous ascomycete fungi present in soils or growing on wood, bark and other fungi (mycoparasite) (Druzhinina et al., 2011). This genus is highly opportunistic and adaptable to several environments, with some strains applied for biocontrol of fungal phytopathogens. Trichoderma reesei is capable of decomposing woody and herbaceous materials and is an important industrial producer of hemicellulolytic enzymes (Martinez et al., 2008; Druzhinina et al., 2011).

As expected, the classification of fungal sequences in guilds in the current study revealed that the most abundant fungi were ectomycorrhizal (ECM) fungi and saprotrophs related to organic material decomposition (Valášková et al., 2009; Urbanová et al., 2015). Many species of ECM fungi act as decomposers based on the expression of extracellular enzymes (Bödeker et al., 2009). Burke et al. (2014) indicated that enzyme activity varies greatly among ECM fungi, with some species producing enzymes at levels equivalent to those of saprotrophic fungi.

\subsection{Co-occurrence and active potential interactions}

Co-inertia analysis revealed significant co-variance between the fungal and bacterial communities, suggesting overall relationships between kingdoms. However, the co-occurrence networks showed that the overall number of connections between microbes was higher in the "heavy" fraction (377) than in either control treatment. The number of fungal genera connected to bacterial genera was lowest in the "heavy" fraction co-occurrence network (2), indicating that potential direct interactions between kingdoms did not increase during the assimilation of the EPS. Shorter arrows in co-inertia analysis for the heavy fraction, however, indicated a stronger relationship between bacterial and fungal communities, which could be due to indirect exchange of metabolites and use of fungal byproducts. Nonetheless, the assimilation of the EPS induced an increase in the potential interactions particularly among bacterial taxa, as observed in the number of edges in the "heavy" fraction network (377). These dynamics were not observed in the EPSamended control network; nevertheless, not all taxa in this treatment are directly involved in the metabolism of the biopolymer. In addition, Singulisphaera had fewer potential interactions, with a variety of microorganisms from different phyla that have either cellulolytic capacity or the ability to remove toxic compounds (Valášková et al., 2009; Kielak et al., 2016b). Granulicella did not show any strong connection with any taxa in both control treatments.

Fungi are thought to be the main players in the decomposition of recalcitrant materials such as lignocellulose, followed by bacterial decomposition of polysaccharides and polymeric compounds (Boer et al., 2005; Romaní et al., 2006). In the "heavy" fraction, however, only 8 fungal groups, such as Unclassified Leotiomycetes and the white-rot genus Hypholoma were observed. The fungal groups were mainly positively connected to each other, and negatively with unclassified groups of Planctomycetes, indicating competition for the carbon resources derived from the EPS, which hypothesis is supported by the high glycolytic capacity observed in both groups of microorganisms.

The most abundant bacterial genus in the "heavy" fraction, Singulisphaera, had mostly positive connections, especially with other groups of Planctomycetes, Actinobacteria and Verrucomicrobia, suggesting potential 
cooperation for metabolizing WH15EPS. Several studies demonstrate that those groups of bacteria have glycolytic and detoxifying capacities, producing several enzymes that could be involved in the degradation of the EPS and resource sharing (Martinez-Garcia et al., 2012; Uhlik et al., 2012; Ivanova et al., 2017b). In addition, no direct correlation was found between Singulisphaera and the EPS producer Granulicella, which suggests that the metabolism of WH15EPS by Singulisphaera and enrichment of the genus did not negatively impact the abundance of Granulicella. This might be because of high amount of EPS added in the microcosm experiment. By contrast, Granulicella had a negative correlation with groups of Actinobacteria, demonstrating a potential competition, where Actinobacteria are metabolizing WH15EPS and impacting negatively Granulicella. Actinobacteria are widely spread in the environment and play an essential role in carbon cycling, presenting a wide range of extracellular enzymes (Lacombe-Harvey et al., 2018). Furthermore, the presence of Granulicella in the heavy fraction demonstrates the capacity of the genus to use EPS as a carbon source; however, there is no experimental evidence that the producer strain is able to metabolize its own EPS. It must be noted that the analysis of co-occurrence networks derived from labeled and unlabeled EPS treatments demonstrated that the treatment based on unlabeled total DNA may not reflect real co-occurrence among microorganisms, suggesting this that type of analysis can yield misleading ecological inferences. Even though network analysis has been a widely used approach in ecology, it still lacks experimental validation, especially due to technical limitations, such as the complexity of microbial ecosystems and the high number of uncultivated microorganisms (Berry and Widder, 2014). It has been observed that connections demonstrated by microbial networks do not necessarily represent real interactions (Faust and Raes, 2016), but predictions of potential interactions, which can also be indirect, and that the results of those evaluations should be interpreted carefully. Nonetheless, despite these limitations, co-occurrence network analysis can still lead to innovative insights into the structure of microbial communities (Faust and Raes, 2016) and establish a fundamental basis for more mechanistic studies of Acidobacteria and other uncultivated microbes. For instance, as shown in our study, the detection of Singulisphaera as the most abundant genus in the labeled treatment, as well as its connections to other microorganisms as shown in the "heavy" fraction network would not be possible in studies solely based on total DNA, due to the low relative abundance of such bacteria.

Several bacterial and fungal taxa have the ability and potential to metabolize the EPS of Granulicella sp. strain WH15. It is not possible to quantify the amount of EPS produced only by this genus in the natural environment; however, our study revealed active potential interactions between microorganisms in their natural habitat when EPS was added as carbon source. In addition, the structure of the co-occurrence network of microorganisms able to metabolize EPS differed from those in the control treatments, particularly in unlabeled EPS control, demonstrating that hidden potential interactions can be unraveled by more specific metabolism studies. Finally, the number of potential associations with uncultured and unclassified taxa reinforces that further efforts are needed to characterize these groups to better understand their functions in the environment.

\section{Declaration of competing interest}

The authors declare that they have no known competing financial interests or personal relationships that could have appeared to influence the work reported in this paper.

\section{Acknowledgments}

We would like to thank Wietse de Boer for helping with the sampling local, Hans Zweers for the GC measurements, Késia Lourenço for helping with soil analyses and Jos Raaijmakers and Marcio Leite for comments on the manuscript. O.Y.A. Costa was supported by an SWB grant from
CNPq [202496/2015-5] (Conselho Nacional de Desenvolvimento Científico e Tecnológico). Number 6994 of the Netherlands Institute of Ecology (NIOO-KNAW).

\section{Appendix A. Supplementary data}

Supplementary data to this article can be found online at https://doi. org/10.1016/j.soilbio.2020.107916.

\section{References}

Bengtsson-Palme, J., Ryberg, M., Hartmann, M., Branco, S., Wang, Z., Godhe, A., De Wit, P., Sánchez-García, M., Ebersberger, I., de Sousa, F., Amend, A.S., Jumpponen, A., Unterseher, M., Kristiansson, E., Abarenkov, K., Bertrand, Y.J.K., Sanli, K., Eriksson, K.M., Vik, U., Veldre, V., Nilsson, R.H., Bunce, M., 2013. Improved software detection and extraction of ITS1 and ITS2 from ribosomal ITS sequences of fungi and other eukaryotes for analysis of environmental sequencing data. Methods Ecol. Evol. 4, 914-919.

Bergmann, G.T., Bates, S.T., Eilers, K.G., Lauber, C.L., Caporaso, J.G., Walters, W.A., Knight, R., Fierer, N., 2011. The under-recognized dominance of Verrucomicrobia in soil bacterial communities. Soil Biology and Biochemistry 43, 1450-1455.

Berry, D., Widder, S., 2014. Deciphering microbial interactions and detecting keystone species with co-occurrence networks. Frontiers in Microbiology 5, 219.

Bödeker, I.T.M., Nygren, C.M.R., Taylor, A.F.S., Olson, Å, Lindahl, B.D., 2009. ClassII peroxidase-encoding genes are present in a phylogenetically wide range of ectomycorrhizal fungi. The ISME Journal 3, 1387-1395.

Boer, W.d., Folman, L.B., Summerbell, R.C., Boddy, L., 2005. Living in a fungal world: impact of fungi on soil bacterial niche development. FEMS Microbiology Reviews 29, 795-811.

Burke, D.J., Smemo, K.A., Hewins, C.R., 2014. Ectomycorrhizal fungi isolated from oldgrowth northern hardwood forest display variability in extracellular enzyme activity in the presence of plant litter. Soil Biology and Biochemistry 68, 219-222.

Bushnell, B., 2015. BBMap. https://sourceforge.net/projects/bbmap/.

Campanharo, J.C., Kielak, A.M., Castellane, T.C.L., Kuramae, E.E., Lemos, E.G.d.M., 2016. Optimized medium culture for Acidobacteria subdivision 1 strains. FEMS Microbiology Letters 363, fnw245.

Cardman, Z., Arnosti, C., Durbin, A., Ziervogel, K., Cox, C., Steen, A.D., Teske, A., Spormann, A.M., 2014. Verrucomicrobia are candidates for polysaccharide-degrading bacterioplankton in an arctic fjord of Svalbard. Applied and Environmental Microbiology 80, 3749-3756.

Costa, O.Y.A., Raaijmakers, J.M., Kuramae, E.E., 2018. Microbial extracellular polymeric substances: ecological function and impact on soil aggregation. Frontiers in Microbiology 9, 1636.

Doncheva, N.T., Assenov, Y., Domingues, F.S., Albrecht, M., 2012. Topological analysis and interactive visualization of biological networks and protein structures. Nature Protocols 7, 670-685.

Dray, S., Dufour, A.-B., 2007. The ade4 Package: implementing the duality diagram for ecologists. Journal of Statistical Software 22, 1-20.

Druzhinina, I.S., Seidl-Seiboth, V., Herrera-Estrella, A., Horwitz, B.A., Kenerley, C.M., Monte, E., Mukherjee, P.K., Zeilinger, S., Grigoriev, I.V., Kubicek, C.P., 2011. Trichoderma: the genomics of opportunistic success. Nature Reviews Microbiology 9, 749-759.

DuBois, M., Gilles, K.A., Hamilton, J.K., Rebers, P.A., Smith, F., 1956. Colorimetric method for determination of sugars and related substances. Analytical Chemistry 28, $350-356$.

Edgar, R.C., 2010. Search and clustering orders of magnitude faster than BLAST. Bioinformatics 26, 2460-2461.

Edgar, R.C., Haas, B.J., Clemente, J.C., Quince, C., Knight, R., 2011. UCHIME improves sensitivity and speed of chimera detection. Bioinformatics 27, 2194-2200.

Faria, M., Bordin, N., Kizina, J., Harder, J., Devos, D., Lage, O.M., 2018. Planctomycetes attached to algal surfaces: insight into their genomes. Genomics 110, 231-238.

Faust, K., Raes, J., 2016. CoNet app: inference of biological association networks using Cytoscape. F1000Research 5, 1519.

Flemming, H.-C., Wingender, J., 2010. The biofilm matrix. Nature Reviews Microbiology 8, 623-633.

Friedman, J., Alm, E.J., 2012. Inferring correlation networks from genomic survey data. PLoS Computational Biology 8, e1002687.

Ginige, M.P., Hugenholtz, P., Daims, H., Wagner, M., Keller, J., Blackall, L.L., 2004. Use of stable-isotope probing, full-cycle rRNA analysis, and fluorescence in situ hybridization-microautoradiography to study a methanol-fed denitrifying microbial community. Applied and Environmental Microbiology 70, 588-596.

Hollander, M.D., 2017. Nioo-Knaw/Hydra: 1.3.3. Zenodo. https://zenodo. org/record/884028\#.XvSr9WgzZPY.

Ivanova, A.O., Dedysh, S.N., 2012. Abundance, diversity, and depth distribution of Planctomycetes in acidic northern wetlands. Frontiers in Microbiology 3, 9.

Ivanova, A.A., Naumoff, D.G., Miroshnikov, K.K., Liesack, W., Dedysh, S.N., 2017b. Comparative genomics of four Isosphaeraceae Planctomycetes: a common pool of plasmids and glycoside hydrolase genes shared by Paludisphaera borealis PX4T, Isosphaera pallida IS1BT, Singulisphaera acidiphila DSM 18658T, and strain SH-PL62. Frontiers in Microbiology 8, 801-809.

Ivanova, A.A., Wegner, C.-E., Kim, Y., Liesack, W., Dedysh, S.N., 2017a. Metatranscriptomics reveals the hydrolytic potential of peat-inhabiting Planctomycetes. Antonie Van Leeuwenhoek 111, 801-809. 
Jeffries, P., 1999. Scleroderma. In: Cairney, J.W.G., Chambers, S.M. (Eds.), Ectomycorrhizal Fungi Key Genera in Profile, 1 ed. Springer, Berlin, pp. 187-200.

Johnson, J.M., Ludwig, A., Furch, A., Mithöfer, A., Scholz, S.S., Reichelt, M., Oelmüller, R., 2018. The beneficial root-colonizing fungus Mortierella hyalina promotes the aerial growth of Arabidopsis and activates calcium-dependent responses which restrict Alternaria brassicae-induced disease development in roots. Molecular Plant-Microbe Interactions 32, 351-363.

Kielak, A.M., Barreto, C.C., Kowalchuk, G.A., van Veen, J.A., Kuramae, E.E., 2016a. The ecology of acidobacteria: moving beyond genes and genomes. Frontiers in Microbiology 7, 744.

Kielak, A.M., Castellane, T.C.L., Campanharo, J.C., Colnago, L.A., Costa, O.Y.A., Corradi da Silva, M.L., van Veen, J.A., Lemos, E.G.M., Kuramae, E.E., 2017. Characterization of novel Acidobacteria exopolysaccharides with potential industrial and ecological applications. Scientific Reports 7, 41193.

Kielak, A.M., Scheublin, T.R., Mendes, L.W., van Veen, J.A., Kuramae, E.E., 2016b. Bacterial community succession in pine-wood decomposition. Frontiers in Microbiology 7, 231.

Kõljalg, U., Nilsson, R.H., Abarenkov, K., Tedersoo, L., Taylor, A.F.S., Bahram, M., Bates, S.T., Bruns, T.D., Bengtsson-Palme, J., Callaghan, T.M., Douglas, B., Drenkhan, T., Eberhardt, U., Dueñas, M., Grebenc, T., Griffith, G.W., Hartmann, M. Kirk, P.M., Kohout, P., Larsson, E., Lindahl, B.D., Lücking, R., Martín, M.P., Matheny, P.B., Nguyen, N.H., Niskanen, T., Oja, J., Peay, K.G., Peintner, U., Peterson, M., Põldmaa, K., Saag, L., Saar, I., Schüßler, A., Scott, J.A., Senés, C., Smith, M.E., Suija, A., Taylor, D.L., Telleria, M.T., Weiss, M., Larsson, K.-H., 2013. Towards a unified paradigm for sequence-based identification of fungi. Molecular Ecology 22, 5271-5277.

Koster, J., Rahmann, S., 2012. Snakemake-a scalable bioinformatics workflow engine. Bioinformatics 28, 2520-2522.

Kulichevskaya, I.S., Ivanova, A.O., Baulina, O.I., Bodelier, P.L.E., Damste, J.S.S., Dedysh, S.N., 2008. Singulisphaera acidiphila gen. nov., sp. nov., a non-filamentous, Isosphaera-like planctomycete from acidic northern wetlands. International Journal of Systematic and Evolutionary Microbiology 58, 1186-1193.

Kuramae, E.E., Yergeau, E., Wong, L.C., Pijl, A.S., Veen, J.A., Kowalchuk, G.A., 2012. Soil characteristics more strongly influence soil bacterial communities than land-use type. FEMS Microbiology Ecology 79, 12-24.

Kuznetsova, A., Brockhoff, P.B., Christensen, R.H.B., 2017. lmerTest package: tests in linear mixed effects models. Journal of Statistical Software 82, 1-26.

Lacombe-Harvey, M.-E., Brzezinski, R., Beaulieu, C., 2018. Chitinolytic functions in actinobacteria: ecology, enzymes, and evolution. Applied Microbiology and Biotechnology 102, 7219-7230.

Legendre, P., Gallagher, E.D., 2001. Ecologically meaningful transformations for ordination of species data. Oecologia 129, 271-280.

Liu, H., Fang, H.H., 2002. Extraction of extracellular polymeric substances (EPS) of sludges. Journal of Biotechnology 95, 249-256.

Lupatini, M., Suleiman, A.K.A., Jacques, R.J.S., Antoniolli, Z.I., de Siqueira Ferreira, A.o., Kuramae, E.E., Roesch, L.F.W., 2014. Network topology reveals high connectance levels and few key microbial genera within soils. Front. Environ. Sci. 2, 1-11.

Madsen, E.L., 2006. The use of stable isotope probing techniques in bioreactor and field studies on bioremediation. Current Opinion in Biotechnology 17, 92-97.

Makowski, D., 2018. The psycho package: an efficient and publishing-oriented workflow for psychological science. J. Open Sourc. Softw. 3, 470.

Martinez-Garcia, M., Brazel, D.M., Swan, B.K., Arnosti, C., Chain, P.S.G., Reitenga, K.G., Xie, G., Poulton, N.J., Gomez, M.L., Masland, D.E.D., Thompson, B., Bellows, W.K., Ziervogel, K., Lo, C.-C., Ahmed, S., Gleasner, C.D., Detter, C.J., Stepanauskas, R., 2012. Capturing single cell genomes of active polysaccharide degraders: an unexpected contribution of Verrucomicrobia. PLoS One 7, e35314.

Martinez, D., Berka, R.M., Henrissat, B., Saloheimo, M., Arvas, M., Baker, S.E., Chapman, J., Chertkov, O., Coutinho, P.M., Cullen, D., Danchin, E.G.J., Grigoriev, I. V., Harris, P., Jackson, M., Kubicek, C.P., Han, C.S., Ho, I., Larrondo, L.F., de Leon, A. L., Magnuson, J.K., Merino, S., Misra, M., Nelson, B., Putnam, N., Robbertse, B., Salamov, A.A., Schmoll, M., Terry, A., Thayer, N., Westerholm-Parvinen, A., Schoch, C.L., Yao, J., Barabote, R., Nelson, M.A., Detter, C., Bruce, D., Kuske, C.R., Xie, G., Richardson, P., Rokhsar, D.S., Lucas, S.M., Rubin, E.M., Dunn-Coleman, N., Ward, M., Brettin, T.S., 2008. Genome sequencing and analysis of the biomassdegrading fungus Trichoderma reesei (syn. Hypocrea jecorina). Nature Biotechnology $26,553-560$

Masuko, T., Minami, A., Iwasaki, N., Majima, T., Nishimura, S.-I., Lee, Y.C., 2005. Carbohydrate analysis by a phenol-sulfuric acid method in microplate format. Analytical Biochemistry 339, 69-72.

McDonald, D., Clemente, J.C., Kuczynski, J., Rideout, J.R., Stombaugh, J., Wendel, D., Wilke, A., Huse, S., Hufnagle, J., Meyer, F., Knight, R., Caporaso, J.G., 2012. The Biological Observation Matrix (BIOM) format or: how I learned to stop worrying and love the ome-ome. GigaScience 1, 7.

McMurdie, P.J., Holmes, S., 2013. phyloseq: an r package for reproducible interactive analysis and graphics of microbiome census data. PLoS One 8, e61217.

Mendiburu, F.d., 2017. Statistical procedures for agricultural research. R Package Version 1.2-3. http://CRAN.R-project.org/package=agricolae.

Moore, E.K., Villanueva, L., Hopmans, E.C., Rijpstra, W.I.C., Mets, A., Dedysh, S.N., Sinninghe Damsté, J.S., Schloss, P.D., 2015. Abundant trimethylornithine lipids and specific gene sequences are indicative of Planctomycete importance at the oxic/ anoxic interface in sphagnum-dominated Northern Wetlands. Applied and Environmental Microbiology 81, 6333-6344.

Nalin, R., Simonet, P., Vogel, T.M., Normand, P., 1999. Rhodanobacter lindaniclasticus gen. nov., sp. nov., a lindane-degrading bacterium. Int. J. Syst. Bacteriol. 49, 19-23.
Navarrete, A.A., Kuramae, E.E., de Hollander, M., Pijl, A.S., van Veen, J.A., Tsai, S.M., 2013. Acidobacterial community responses to agricultural management of soybean in Amazon forest soils. FEMS Microbiology Ecology 83, 607-621.

Navarrete, A.A., Tsai, S.M., Mendes, L.W., Faust, K., de Hollander, M., Cassman, N.A., van Veen, J.A., Kuramae, E.E., 2015. Soil microbiome responses to the short-term effects of Amazonian deforestation. Molecular Ecology 24, 2433-2448.

Neufeld, J.D., Vohra, J., Dumont, M.G., Lueders, T., Manefield, M., Friedrich, M.W., Murrell, J.C., 2007. DNA stable-isotope probing. Nature Protocols 2, 860-866.

Nguyen, N.H., Song, Z., Bates, S.T., Branco, S., Tedersoo, L., Menke, J., Schilling, J.S., Kennedy, P.G., 2016. FUNGuild: an open annotation tool for parsing fungal community datasets by ecological guild. Fungal Ecol. 20, 241-248.

Oksanen, J., Blanchet, F.G., Friendly, M., Kindt, R., Legendre, P., McGlinn, D., Minchin, P.R., O'Hara, R.B., Simpson, G.L., Solymos, P., Stevens, M.H.H., Szoecs, E., Wagner, H., 2018. vegan: community ecology package. R package version 2.4-6. http s://cran.r-project.org/web/packages/vegan/vegan.pdf.

Padmanabhan, P., Padmanabhan, S., DeRito, C., Gray, A., Gannon, D., Snape, J.R., Tsai, C.S., Park, W., Jeon, C., Madsen, E.L., 2003. Respiration of 13C-labeled substrates added to soil in the field and subsequent 16S rRNA gene analysis of 13clabeled soil DNA. Applied and Environmental Microbiology 69, 1614-1622.

Pan, Y., Cassman, N., de Hollander, M., Mendes, L.W., Korevaar, H., Geerts, R.H.E.M., van Veen, J.A., Kuramae, E.E., 2014. Impact of long-term N, P, K, and NPK fertilization on the composition and potential functions of the bacterial community in grassland soil. FEMS Microbiology Ecology 90, 195-205.

Pruesse, E., Peplies, J., Glöckner, F.O., 2012. SINA: accurate high-throughput multiple sequence alignment of ribosomal RNA genes. Bioinformatics 28, 1823-1829.

R Core Team, 2015. R: A Language and Environment for Statistical Computing. R Foundation for Statistical Computing, Vienna. http://Www.R-Project.Org/.

Rognes, T., Mahé, F., xflouris, 2015. vsearch: VSEARCH version 1.0.16. https://github. com/torognes/vsearch.

Romaní, A.M., Fischer, H., Mille-Lindblom, C., Tranvik, L.J., 2006. Interactions of bacteria and fungi on decomposing litter: differential extracellular enzyme activities. Ecology 87, 2559-2569.

Schlemper, T.R., van Veen, J.A., Kuramae, E.E., 2017. Co-variation of bacterial and fungal communities in different sorghum cultivars and growth stages is soil dependent. Microbial Ecology 76, 205-214.

Schlesner, H., 1994. The development of media suitable for the microorganisms morphologically resembling Planctomyces spp., Pirellula spp., and other Planctomycetales from various aquatic habitats using dilute media. Systematic \& Applied Microbiology 17, 135-145.

Shannon, P., 2003. Cytoscape: a software environment for integrated models of biomolecular interaction networks. Genome Research 13, 2498-2504.

Singleton, D.R., Powell, S.N., Sangaiah, R., Gold, A., Ball, L.M., Aitken, M.D., 2005. Stable-isotope probing of bacteria capable of degrading salicylate, naphthalene, or phenanthrene in a bioreactor treating contaminated soil. Applied and Environmental Microbiology 71, 1202-1209.

Song, M., Jiang, L., Zhang, D., Luo, C., Wang, Y., Yu, Z., Yin, H., Zhang, G., 2016 Bacteria capable of degrading anthracene, phenanthrene, and fluoranthene as revealed by DNA based stable-isotope probing in a forest soil. Journal of Hazardous Materials 308, 50-57.

Spring, S., Bunk, B., Spröer, C., Schumann, P., Rohde, M., Tindall, B.J., Klenk, H.-P., 2016. Characterization of the first cultured representative of Verrucomicrobia subdivision 5 indicates the proposal of a novel phylum. The ISME Journal 10, 2801-2816.

Štursová, M., Žifč́ková, L., Leigh, M.B., Burgess, R., Baldrian, P., 2012. Cellulose utilization in forest litter and soil: identification of bacterial and fungal decomposers. FEMS Microbiology Ecology 80, 735-746.

Uhlik, O., Wald, J., Strejcek, M., Musilova, L., Ridl, J., Hroudova, M., Vlcek, C., Cardenas, E., Mackova, M., Macek, T., 2012. Identification of bacteria utilizing biphenyl, benzoate, and naphthalene in long-term contaminated soil. PLoS One 7 , e40653.

Urbanová, M., Šnajdr, J., Baldrian, P., 2015. Composition of fungal and bacterial communities in forest litter and soil is largely determined by dominant trees. Soil Biology and Biochemistry 84, 53-64.

Valášková, V., de Boer, W., Klein Gunnewiek, P.J.A., Pospíšek, M., Baldrian, P., 2009. Phylogenetic composition and properties of bacteria coexisting with the fungus Hypholoma fasciculare in decaying wood. The ISME Journal 3, 1218-1221.

van Bueren, A.L., Saraf, A., Martens, E.C., Dijkhuizen, L., Drake, H.L., 2015. Differential metabolism of exopolysaccharides from probiotic Lactobacilli by the human gut symbiont Bacteroides thetaiotaomicron. Applied and Environmental Microbiology 81, 3973-3983.

Verastegui, Y., Cheng, J., Engel, K., Kolczynski, D., Mortimer, S., Lavigne, J., Montalibet, J., Romantsov, T., Hall, M., McConkey, B.J., Rose, D.R., Tomashek, J.J., Scott, B.R., Charles, T.C., Neufeld, J.D., 2014. Multisubstrate isotope labeling and metagenomic analysis of active soil bacterial communities. mBio 5 e01157-01114.

Wang, J., Jenkins, C., Webb, R.I., Fuerst, J.A., 2002. Isolation of gemmata-like and isosphaera-like planctomycete bacteria from soil and freshwater. Applied and Environmental Microbiology 68, 417-422.

Wang, X., Sharp, C.E., Jones, G.M., Grasby, S.E., Brady, A.L., Dunfield, P.F., Nojiri, H., 2015. Stable-isotope probing identifies uncultured Planctomycetes as primary degraders of a complex heteropolysaccharide in soil. Applied and Environmental Microbiology 81, 4607-4615.

Ward, N.L., Challacombe, J.F., Janssen, P.H., Henrissat, B., Coutinho, P.M., Wu, M., Xie, G., Haft, D.H., Sait, M., Badger, J., Barabote, R.D., Bradley, B., Brettin, T.S., Brinkac, L.M., Bruce, D., Creasy, T., Daugherty, S.C., Davidsen, T.M., Deboy, R.T., Detter, J.C., Dodson, R.J., Durkin, A.S., Ganapathy, A., Gwinn-Giglio, M., Han, C.S., Khouri, H., Kiss, H., Kothari, S.P., Madupu, R., Nelson, K.E., Nelson, W.C., 
Paulsen, I., Penn, K., Ren, Q.H., Rosovitz, M.J., Selengut, J.D., Shrivastava, S., Sullivan, S.A., Tapia, R., Thompson, L.S., Watkins, K.L., Yang, Q., Yu, C.H., Zafar, N., Zhou, L.W., Kuske, C.R., 2009. Three genomes from the phylum Acidobacteria provide insight into the lifestyles of these microorganisms in soils. Applied and Environmental Microbiology 75, 2046-2056.

Webster, N.S., Taylor, M.W., Behnam, F., Lücker, S., Rattei, T., Whalan, S., Horn, M., Wagner, M., 2009. Deep sequencing reveals exceptional diversity and modes of transmission for bacterial sponge symbionts. Environmental Microbiology 12, 2070-2082.

Whang, K.S., Lee, J.C., Lee, H.R., Han, S.I., Chung, S.H., 2014. Terriglobus tenax sp. nov., an exopolysaccharide-producing acidobacterium isolated from rhizosphere soil of a medicinal plant. International Journal of Systematic and Evolutionary Microbiology $64,431-437$.
White, Bruns, T., Lee, S., Taylor, J., 1990. Amplification and Direct Sequencing of Fungal Ribosomal RNA Genes for Phylogenetics, PCR - Protocols and Applications - A Laboratory Manual. Academic Press, pp. 315-322.

Wickham, H., 2016. ggplot2. Use R!. https://ggplot2.tidyverse.org/.

Wiegand, S., Jogler, M., Jogler, C., 2018. On the maverick Planctomycetes. FEMS Microbiology Reviews 42, 739-760.

Wingender, J., Neu, T.R., Flemming, H.-C., 1999. What arebacterial extracellular polymeric substances? In: Wingender, J., Neu, T.R., Flemming, H.-C. (Eds.), Microbial Extracellular Polymeric Substances: Characterization, Structure and Function. Springer Berlin Heidelberg, Berlin, pp. 1-19.

Zhang, Y., Deng, W., Xie, X., Jiao, N., 2016. Differential incorporation of carbon substrates among microbial populations identified by field-based, DNA stableisotope probing in South China sea. PLoS One 11, e0157178. 